Viti iXII ${ }^{\text {te }}$ i Botimit, Nr.1-2,

Dhjetor 2020

\title{
PËRDORIMI I TEKNIKAVE TË POSAÇME TË HETIMIT TË VEPRAVE PENALE DHE PRAKTIKA E GJYKATËS EUROPIANE TË TË DREJTAVE TË NJERIUT.
}

\author{
Ina Hasankolli*
}

\section{*Specialiste, Drejtoria e Përgjithshme e Tatimeve}

Adresë kontakti: inahasankolli@yahoo.com

\section{Përmbledhje}

Objektivi: Objektivi i këtij punimi është të trajtojë në mënyrë më të detajuar përdorimin e teknikave të posaçme të hetimit si një nevojë e shteteve në luftën kundër krimit të organizuar. Gjithashtu të trajtojë raportin mes përdorimit të këtyre teknikave të posaçme të hetimit dhe neninit 8 të Konventës Europiane për të Drejtat e Njeriut (KEDNJ), të drejtës për jetë private dhe familjare. Rastet e devijimit nga kjo e drejtë për shkak të interesit publik dhe qëndrimet e Gjykatës Europiane të të Drejtave të Njeriut (GJEDNJ) lidhur me këtë çështje.

Metoda: Metoda e përdorur në këtë punim synon të trajtojë më hollësisht legjislacionin shqiptar lidhur me teknikat e posaçme të hetimit. Gjithashtu është bërë një ndërthurje me praktikën e GJEDNJ-së lidhur me aplikim në praktikë të këtyre teknikave në luftën kundër krimit të organizuar.

Rezultatet: Në vijim paraqiten raste kur e drejta për jetë private dhe familjare si një e drejtë jo absolute vihet në diskutim kur lind nevoja të përdoren teknikat e posaçme të hetimit. Gjithashtu trajtohen dhe rastet, mënyra dhhe kushtet e domosdoshme që duhet të ekzistojnë për të aplikuar metodat e posaçme të hetimit.

Përfundimet: Me ndryshimet e bëra në Kodin e Procedurës Penale, legjislacioni shqiptar është përshtatur me atë europian, duke arritur të inplementojë praktikat më të mira europiane si dhe praktikat e GJEDNJ-së.

Fjalë çelës: e drejta për jetë private dhe familjare; teknika të posaçme hetimi; veprimet simuluese; agjent $i$ infiltruar; dorëzim i kontrolluar. 
Ina Hasankolli

\section{USE OF SPECIAL TECHNIQUES FOR INVESTIGATING CRIMINAL OFFENSES AND THE PRACTICE OF THE EUROPEAN COURT OF HUMAN RIGHTS}

\section{Abstract}

Objective: The objective of this paper is to address in more detail the use of special investigation techniques as a need of states in the fight against organized crime. Also address the relationship between the use of these special investigative techniques and Article 8 of the European Convention on Human Rights (ECHR), the right to respect for private and family life. Cases of deviation from this right due to the public interest and the views of the European Court of Human Rights (ECHR) on this issue.

Method: The method used in this paper aims to deal in greater detail with the Albanian legislation regarding special investigation techniques. There has also been an overlap with the ECtHR's practice of applying these techniques to the fight against organized crime.

Results: The following are cases where right to respect for private and family life as an absolute right is questioned when the need to use special investigative techniques. The cases, ways and conditions necessary to apply the special investigative methods are also addressed.

Conclusions: With the amendments made to the Criminal Procedure Code, the Albanian legislation has been adapted to the European one, achieving the implementation of European best practices as well as ECHR practices.

Key words: right to respect for private and family life; special investigation techniques; simulation actions; infiltrated agent; controlled delivery.

\section{Hyrje}

Të drejtat e njeriut qëndrojnë në themelet e ndërtimit dhe funksionimit të çdo shoqërie. Shteti në vetvete është garant i këtyre të drejtave, ai ka detyrimin pozitiv t'i garantojë çdo qytetari të tij, të drejtat e njohura në kushtetutë si dhe në instrumentat ndërkombëtarë. Ashtu siç shteti ka detyrimin pozitiv për t'i garantuar këto të drejta ka dhe detyrimin negativ për të mos i cënuar ato, por sa është e mundur të arrihet kjo? A mundet shteti që në çdo rast të garantojë në mënyrë absolute të drejtat e individit, apo mund të cedohet nga këto të drejta për interesa të tjera më të larta?

Krimi i organizuar sot ka marrë përmasa transkufitare dhe gjithëpërfshirëse, për këtë arsye shteteve u ka lindur nevoja për të gjetur mënyrat dhe teknikat e duhura për të luftuar këtë 1loj krimi, i cili sa vjen dhe perfeksionohet. Një problem i madh mund të shtrohet këtu lidhur me dilemën se sa efektive janë metodat e përdorura nga shtetet dhe a cënojnë ato të drejtat e njeriut, në çastin që fillojnë të aplikohen? 
PËRDORIMI I TEKNIKAVE TË POSAÇME TË HETIMIT TË VEPRAVE PENALE DHE PRAKTIKA E GJYKATËS EUROPIANE TË TË DREJTAVE TË NJERIUT.

Një nga të drejtat themelore të njeriut është e drejta për jetë private dhe familjare e cila parashikohet në nenin 8 të Konventës Europiane të të Drejtave të Njeriut (KEDNJ, në vijim konventa). Ky nen është mbase më i prekuri nga metodat e posaçme të hetimit në luftën kundër krimit të organizuar. Jeta private dhe familjare është mjaft komplekse duke mos pasur dhe një përkufizim fiks të saj në instrumentat ndërkombëtare. Nga ana tjetër ekziston një praktikë e gjërë e Gjykatës Europiane të të Drejtave të njeriut (GJEDNJ) lidhur me të, të cilës do t’i referohemi në vijim të këtij punimi. Teknikat e posaçme të hetimit (veprimet simuluese; agjenti i infiltruar apo dorëzimi i kontrolluar) në shumë raste mund të cënojnë drejtpërsëdrejti këtë të drejtë.

Teknikat e posaçme të hetimit të parashikuara nga legjislacioni ynë procedurial penal kanë pësuar një sërë ndryshimesh. Gjithashtu përveç dy teknikave ekzistuese siç kanë qënë agjenti i infiltruar dhe veprimet simuluese është shtuar dhe dorëzimi i kontrolluar i cili më parë ka qënë i parashikuar me ligjin nr.8750, datë 26.3.2001 "Për parandalimin dhe luftën ndaj trafikut të substancave narkotike ose psikotrope".

Këto ndryshime janë bërë në funksion të përshtatjes me metodat më të mira ndërkombëtare në luftën kundër krimit të organizuar. Por si qëndron raporti midis zbatimit të këtyre teknikave të posaçme të hetimit me respektimin e të drejtës për jetë private dhe familjare?

Gjykata Europiane për të Drejtat e Njeriut ka një praktikë të gjërë lidhur me rastet se kur zbatimi nga ana e shtetetve i teknikave të posaçme të hetimit është vendosur përballë të drejtës për jetë private dhe familjare. Gjithashtu GJEDNJ është munduar që në praktikën e saj të vendosë një sërë kushtesh apo kriteresh të cilat do të mund të kufizonin arbitraritetin e shteteve gjatë zbatimit të teknikave të posaçme të hetimit.

Në këtë mënyrë shtetet duhet t'i përdorin këto mjete te posaçme hetimi në mënyrë sa më efektive duke ruajtur për sa është e mundur një balancë mes respektimit të të drejtës për jetë private dhe familjare dhe luftës kundër krimit të organizuar, që përbën sot një rrezik për gjithë shoqërinë.

\section{Teknikat e posaçme të hetimit sipas legjislacionit shqiptar.}

Në Kodin e procedurës penale parashikohen si teknika të posaçme hetimi përkatësisht: veprimet simuluese; agjenti i infiltruar në grupin kriminal si dhe dorëzimi i kontrolluar. Këto teknika të posaçme hetimi mund të përdoren vetëm atëherë kur përdorimi i teknikave të zakonshme të hetimit do të ishin të papërshtatshme. Pra teknikat e posaçme të hetimit përdoren si metodë e fundit nga ana e organit procedues, kjo për shkak të vetë natyrës së tyre që kërkon kohe, burime, si financiare ashtu dhe njerëzore si dhe mjete e paisje të specializuara. 
Ina Hasankolli

\section{a. Veprimet simuluese}

Veprimet simuluese janë veprime të tilla si blerja apo shitja e simuluar nga ana e oficerit të policisë gjyqësore apo i një personi të autorizuar e sendeve që janë të ndaluara për t'u përdorur, zotëruar, mbajtur apo tregtuar apo sendeve që rrjedhin nga një krim, ose simulimin e një akti korruptiv ose të kryejë veprime të tjera simuluese, për të zbuluar dhe mbledhur prova për personat e dyshuar për kryerjen e një krimi, duke fshehur bashkëpunimin me policinë ose detyrën e tyre si punonjës policie ${ }^{(1)}$.

Sende të tilla mund të jetë çdo send i përjashtuar nga qarkullimi civil të tilla si: lëndët narkotike; veprat e artit; sendet që përbëjnë mjet apo produkt i veprës penale; armët luftarake; mjete që përdoren për falsifikime etj.

Sipas Gjykatës së Lartë veprimet simuluese mund të jenë vetëm tre:

a) blerje e simuluar e sendeve që rrjedhin nga krimi;

b) simulimi i një akti korruptiv;

c) ose për të kryer veprime të tjera simuluesë për të zbuluar të dhëna financiare ose pronësie të një personi ${ }^{(2)}$.

Personi që mund të kryeje veprime simuluese është si agjenti i policisë gjyqësore ashtu edhe një person tjetër i autorizuar prej tij, pra mund ta kryejnë dhe persona të tjerë që nuk janë agjentë policie gjyqësore. Kjo tregon që personi që do të kryejë veprimet simuluese nuk duhet domosdoshmërisht të zotërojë aftësi të veçanta, mjafton që ai të jetë autorizuar për kryerjen e këtij veprimi. Si dhe në çdo rast të fshehë bashkëpunimin e tij me policinë apo detyrën si punonjës policie.

Të gjitha veprimet hetimore kryhen nën autorizimin dhe mbikqyrjen e prokurorit që kontrollon hetimet apo të atij prokurori që ka juridiksion në territorin ku do të zhvillohet veprimi simulues. Pas përfundimit të veprimit simulues policia gjyqësore harton një raport përmbledhës të cilin ja dorëzon prokurorit së bashku me të gjithë provat e mbledhura ${ }^{(3)}$.

Ajo ç'farë duhet pasur parasysh në kryerjen e veprimeve simuluese është se veprimi simulues nuk duhet të provokojë një akt kriminal kundrejt personit tjeter. Pra të shtyjë një person të kryejë një vepër penale të cilin ai në rrethana normale nuk do ta kishte kryer nëse nuk do të ishte ndërhyrja e policisë. Në rast se akti provokohet, pra personi nën nxitjen e agjentit të policisë gjyqësore apo të personit të autorizuar kryen një akt kriminal të cilin nuk do ta kishte kryer në kushte normale, atëherë rezultati i përfituar nga ky veprim simulues nuk mund të përdoret.

Në një vendim të Gjykatës së Lartë, Kolegji Penal është shprehur se: “...agjenti nuk është mjaftuar në hetimin e veprimtarisë kriminale në mënyrë pasive, por ka kryer veprime aktive, duke i kërkuar paisjen me vizë shengen falso, kundrejt shpërblimit. Nuk rezulton që agjenti të ketë konstatuar ekzistencën e ndonjë veprimtarie kriminale, ku ky agjent të ketë qëndruar 
PËRDORIMI I TEKNIKAVE TË POSAÇME TË HETIMIT TË VEPRAVE PENALE DHE PRAKTIKA E GJYKATËS EUROPIANE TË TË DREJTAVE TË NJERIUT.

pasiv" (4). Pra në rast se personi s'do të kishte qënë i provokuar nga ana e policisë ai nuk do e kishte kryer veprën penale. Kjo pasi nuk rezultonte ndonje provë tjetër ku ai të kishte kryer veprën penale pa provokimin e agjentit të policisë.

"Filmimet dhe fotografimet që bëhen në rastin e blerjes së simuluar të narkotikëve duhet të pranohen si provë në përputhje me nenin 151 të KPrP"(5). I cili citon se: "Kur kërkohet një provë e cila nuk rregullohet me ligj, gjykata mund ta marrë nëse ajo vlen për të vërtetuar faktet dhe nuk cënon lirinë e vullnetit të personit”.

\section{b. Agjenti i infiltruar}

Infiltrimi në përbërje të grupit kriminal- kjo teknikë e posaçme hetimi kryhet vetëm për zbulimin e krimeve të rënda dhe vetëm nga oficeri apo agjenti i policisë gjyqësore me autorizimin dhe mbikëqyrjen e prokurorit. Pikërisht këtu qëndron dhe një nga ndryshimet me veprimet simuluese të cilat mund të kryhen si nga ana e agjentit të policisë gjyqësore ashtu edhe nga një person tjetër i autorizuar nga prokurori. Tek infiltrimi në përbërjen e një grupi kriminal personi duhet të jetë domosdoshmërisht oficer ose agjent policie gjyqësore, kjo pasi duhet të zotërojë aftësi të veçanta. Për shkak të rrezikshmërisë të lartë që kanë grupet kriminale ky veprim s'mund të kryhet nga ana e personave të tjerë që nuk i kanë këto cilësi. I rëndësishëm është të theksohet fakti që ai s'mund të hyjë në një grup kriminal që sapo krijohet apo që është në krijim e sipër, por në një grup ekzistent kriminal.

Personi infiltrohet në grupin kriminal me qëllim individualizimin e pjesëtarëve të këtij grupi si dhe për të mbledhur të dhëna të nevojshme për hetimin, duke fshehur në çdo rast bashkëpunimin me policinë apo detyrën e tij si punonjës policie ${ }^{(6)}$.

“Megjithë autorizimin e paligjshëm të prokurorit, veprimet e bëra nga shtetasi X nuk janë gjë tjetër veçëse infiltrim në grupin kriminal, ku ka bërë individualizimin e personave dhe ka mbledhur të dhëna të nevojshme për hetimin. Ky shtetas nuk kishte asnjë të drejtë ligjore për t’i kryer këto veprime e për pasojë rezultatet e përfituara, përfshirë dhe dëshmitë e tij të bëra përpara gjykatës janë të paligjshme dhe nuk mund të përdoren. (7)".

Pra siç është shprehur dhe Kolegji Penal i Gjykatës së Lartë, një nga kushtet themelore të zbatimit të kësaj teknike hetimi është fakti që personi duhet të jetë oficer apo agjent policie. Kjo teknikë hetimi nuk mund të kryhet nga një person i zakonshëm, pasi në çdo rast rezultati i përfituar prej tij do të ishte i papërdorshëm.

Ashtu si dhe te veprimi simulues, punonjësi i policisë gjyqësore i infiltruar në grupin kriminal s'mund të provokojë një akt kriminal që në rast se ai s'do të kishte ndërhyrë, në rrethana normale nuk do të kishte ndodhur. Kur vërtetohet se akti është i provokuar rezultati s'mund të përdoret. 
Ina Hasankolli

Autorizimi i prokurorit duhet të përcaktojë afatin e infiltrimit, që lejohet të zgjatet nga prokurori deri në gjashtë muaj dhe hapësirën e lejueshme për punonjësin e infiltruar, duke treguar, sipas rastit, veprimet e paligjshme që mund të kryejë ai, pa rrezikuar jetën e të tjerëve ${ }^{(8)}$.

Punonjësi i policisë gjyqësore i infiltruar mund të pyetet si dëshmitar. Kur dëshmia e tij është thelbësore për çështjen ajo merret duke respektuar rregullat mbi ruajtjen e fshehtësisë së identitetit të informatorit. Legjislatori i ka garantuar në këtë mënyrë mbrojtje informatorit nga çdo lloj rreziku që mund t'i kanoset atij në rastet e zbulimit të identitetit. Në rastet kur punonjësi i policisë gjyqësore i infiltruar në grupin kriminal nuk thirret e nuk pyetet në cilësinë e dëshmitarit, informacionet e marra prej tij nuk mund të përdoren, kjo pasi nuk është respektuar procedura e parashikuar nga legjislatori për marrjen në pyetje të tyre.

\section{c) Dorëzimi i kontrolluar}

Dorëzimi i kontrolluar ${ }^{(9)}$ është një teknikë e posaçme hetimi e cila është futur si risi me ndryshimet që pësoi kodi i procedurës penale. Dorëzimi i kontrolluar është një teknikë e posaçme hetimi që përfshin dy ose më shumë shtete. Ajo autorizohet nga prokurori që drejton hetimet paraprake, me kërkesë të autoriteteve të huaja.

Dorëzimi i kontrolluar ka pasur një përkufizim më të ndryshëm se ai që ka sot në Kodin e Procedurës Penale. Me dorëzim të kontrolluar kuptohej:

“...veprimtaria e karakterizuar nga përdorimi $i$ metodave gjurmuese-hetimore, për të lejuar kalimin në territorin e një ose më shumë shteteve të substancave narkotike ose psikotrope, të prekursorëve ose substancave të tjera zëvendësuese të tyre, të dërguara në mënyrë të paligjshme, të cilat mbahen nën kontrollin e autoriteteve policore të vendeve të sipërpërmendura për të identifikuar personat e përfshirë në kryerjen e veprave penale... ”(10). Dorëzimi i kontrolluar me përfshirjen e tij në Kodin e Procedurës Penale është bërë më shpjegues dhe më i qartë. Ai mund të kryhet kur ekziston një nga kto kushte: (11)

a) kur personat që dyshohet se janë përfshirë në transportin e paligjshëm të lëndëve narkotike, armëve, sendeve të vjedhura, materialeve eksplozive ose bërthamore, materialeve radioaktive, shumave të parave dhe të ardhurave të tjera produkte të veprës penale ose të sendeve të përdorura si mjet për kryerjen e veprave penale, nuk mund të identifikohen ose arrestohen në mënyra të tjera, si dhe kur identifikimi apo arrestimi i tyre do të dëmtonte hetimet ose do të rrezikonte sigurinë e personave apo dëmtimin ose humbjen e sendeve që transportohen;

b) kur zbulimi $i$ veprave penale dhe marrja e provave është $i$ pamundur ose $i$ vështirë për t'u kryer në mënyra të tjera.

Për dorëzimin e kontrolluar duhet të japin pëlqimin autoritetet e huaja, që sendet e 
PËRDORIMI I TEKNIKAVE TË POSAÇME TË HETIMIT TË VEPRAVE PENALE DHE PRAKTIKA E GJYKATËS EUROPIANE TË TË DREJTAVE TË NJERIUT.

paligjshme apo të dyshimta të hyjnë në territorin e tyre, të kalojnë tranzit apo të dalin nga territori i tyre si dhe të garantojnë mbikëqyrjen e vazhdueshme të hyrjes, kalimit, tranzitit dhe daljes nga territori i tyre të këtyre sendeve. Dorëzimi i kontrolluar kryhet sipas kushteve të përcaktuara nga prokurori, i cili urdhëron kryerjen e tij me akt të arsyetuar, pasi sigurohet se autoritetet e huaja kanë rënë dakord.

Prokurori nxjerr urdhërin ku autorizon kryerjen e dorëzimit të kontrolluar i cili duhet të përmbajë: a) emrin e të dyshuarit ose të pandehurit, nëse është i ditur; b) provat që vërtetojnë natyrën e paligjshme të sendeve që duhet të hyjnë, kalojnë ose dalin nga territori i shtetit dhe mënyrat në të cilat do të kryhet kontrolli ose mbikëqyrja e tyre ${ }^{(12)}$. Ky dorëzim i kontrolluar kryhet nga policia gjyqësore sipas udhëzimeve dhe nën mbikqyrjen e prokurorit.

Prokurori kur ekzistojnë kushtet mund të autorizojë që sendet e paligjshme të zëvendësohen tërrësisht apo pjesërisht. Gjithashtu prokurori përcakton dhe vendin se ku do të vendosen kampionet e marra nga sendet e paligjshme, për t'u ruajtur për arsye procedimi.

Pra siç mund të vihet re dorëzimi i kontrolluar kërkon shumë kohë, mjete financiare, mjaft punonjës policie, paisje mjaft specifike si dhe bashkëpunimin me autoritetet e huaja e cila gjithashtu ka kostot e saj. Ndaj prokurori urdhëron përdorimin e kësaj teknike të posaçme hetimi si masë te fundit për vetë kostot dhe vështirësitë që ajo shfaq.

II. Neni 8 i KEDNJ, e drejta për jetë private dhe familjare dhe praktika e GJEDNJ lidhur me teknikat e posaçme të hetimit.

“Çdo person ka të drejtën e respektimit të jetës private dhe familjare, të banesës dhe korrespondencës." (13)

Nga ky nen rrjedh detyrimi i shteteve për të ndërmarë masat e nevojshme në legjislacionin e tyre për te garantuar të drejtën për jetë private dhe familjare. Koncepti e drejtë private dhe familjare mund të shihet në një spektër mjaft të gjërë, pra nuk ekziston një përkufizim ekzakt i saj. Megjithatë GJEDNJ është munduar të japë një përkufizim sa më gjithëpërfshirës. E drejta për jetë private dhe familjare përfshin të drejtën e individit për të vendosur e zhvilluar marrëdhënie me të tjerët, ku banesë nuk do të jetë vetëm vendi ku jetohet dhe zhvillohet jeta familjare, por dhe ambientin ku punon një person i cili ushtron një profesion të lirë (14).

Sipas GJEDNJ nga ky nen nuk përfiton vetëm personi fizik, por dhe ai juridik duke konsideruar si banesë për këtë të fundit selinë, agjensinë apo ambjentet e saj profesionale. Jeta private dhe familjare cënohet në zbatimin e metodave të posaçme të hetimit e më konkretisht nëpërmjet agjentit të infiltruar. Për këtë GJEDNJ ka një praktikë të gjërë në jurisprudencën e saj. 
Ina Hasankolli

Tek çështja Ludi kundër Zvicrës, GJEDNJ doli në konkluzionin se nuk kishte shkelje të nenit 8 të KEDNJ, ndonëse agjenti i infiltruar kishte hyre në banesën e personit dhe kishte krijuar një lidhje shoqërore me të me qëllimi për të zbuluar veprën penale. Gjykata thoshte se duke qënë se personi po kryente një vepër penale ai vetë duhet të mendonte se rrezikonte të takonte një punonjës policie të infiltruar ${ }^{(15)}$. Por gjykata linte pa argumentuar faktin se nëse kjo hipoteze s'do të mund të provohej nga ana e agjentit të infiltruar, atëherë do të ishim përpara cënimit të jetës private dhe familjare të personit.

“Autoriteti publik nuk mund të ndërhyjë në ushtrimin e kësaj të drejte, përveçëse në shkallën e parashikuar nga ligji dhe kur është e nevojshme në një shoqëri demokratike në interes të sigurisë publike për mbrojtjen e rendit publik, shëndetit ose moralit ose për mbrojtjen e të drejtave dhe lirive të individit." (16)

Pra është pikërisht paragrafi i dytë i nenit 8 të KEDNJ, që legjitimon shtetet që në bazë të legjislacionit të tyre të ndërmarin masat e nevojshme duke ndërhyrë në jetën private dhe familjare të një personi tjetër, për mbrojtjen e një interesi më të lartë siç mund të jetë: siguria publike; rendi publik; shëndeti apo morali i personave apo të drejtat dhe liritë themelore të tyre. Shtetet kanë marzh të gjërë vlerësimi, nga parashikimi i bërë në këtë nen del se e drejta për jetë private dhe familjare nuk është një e drejtë absolute.

Gjykata Europiane e të Drejtave të Njeriut ka vendosur disa kritere bazë në mënyrë që teknikat e posaçme të hetimit të konsiderohen të ligjshme si dhe provat e marra prej tyre të mund të jenë të përdorshme.

Në çështjen Ramanauskas kundër Lituanisë, GJEDNJ ka konkluduar se oficerët e policisë duhet të kufizojnë veprimtarinë e tyre duke qëndruar pasiv dhe duke hetuar veprimtarinë kriminale në mënyrë pasive. Pasi në rastin konkret gjykata konstatoi mungesën e provave më të hershme në kohë se veprimi simulues, që të vërtetonin se personi do e kishte kryer veprën penale pa qënë i ndikuar nga oficeri i policisë ${ }^{(17)}$.

Një vendim tjetër po kaq i rëndësishëm i GJEDNJ është dhe Teixera de Castro kundër Portugalisë (18). Gjykata konkludoi se:

“...përdorimi i agjentëve të fshehtë duhej të kufizohej si dhe të vendoseshin garanci dhe në rastet e luftës kundër narkotikëve. Interesi publik nuk mund të justifikojë prova të marra si rezultat $i$ nxitjes së policisë. Autoritetet nuk kanë pasur arsye të forta për të dyshuar se ankuesi ishte një trafikant droge" (19)

Pra në këtë çështje GJEDNJ vendosi kriteret se si merren provat gjatë kryerjes së veprimeve simuluese.

Teknikat e posaçme të hetimit siç e kemi përmendur dhe më lart përdoren të fundit ateherë kur metodat e përgjithshme nuk mund të japin rezultat. Pikërisht në këtë çështje kishim të 
PËRDORIMI I TEKNIKAVE TË POSAÇME TË HETIMIT TË VEPRAVE PENALE DHE PRAKTIKA E GJYKATËS EUROPIANE TË TË DREJTAVE TË NJERIUT.

bënim me një operacion të mirëfilltë policor dhe jo fillimisht hetimor, ku të ishin përdorur njëherë metodat e përgjithshme e më tej të vazhdohej me teknikat e posaçme të hetimit.

Nga kjo çështje rrjedh dhe diferenca që ekziston midis agjentit provocatour dhe agjentit nën mbulim. Agjenti nën mbulim është përgjithësisht pasiv, ai nuk kryen veprime nxitëse që ta cojnë personin në kryerjen e veprës penale, ai mbledh prova dhe informacione, por pa provokuar kryerjen e veprës penale. Ndërsa përsa i përket agjentit provocatour ai ka një rol aktiv duke ngritur kurthe e duke kryer veprime provokuese për personin i cili më pas do të shtyhet të kryejë veprën penale.

\section{Përfundime}

Në legjislacionin tonë njihen si teknika të posaçme hetimi: veprimet simuluese dhe agjenti i infiltruar si dhe dorëzimi i kontrolluar. Teknikat e posaçme të hetimit kanë pësuar disa ndryshime me Kodin e ri të Procedurës Penale. Dorëzimi i kontrolluar është një parashikim i ri i këtij kodi, pasi më përpara ai parashikohej vetëm në ligjin "Për parandalimin dhe luftën ndaj trafikut të substancave narkotike ose psikotrope".

Teknikat e posaçme të hetimit mund të përdoren si masë e fundit dhe vetëm atëherë kur çdo masë tjetër nuk do të ishte efektive. Kjo për shkak të vetë natyrës së tyre që kërkon kohe, burime, si financiare ashtu dhe njerëzore si dhe mjete e paisje të specializuara.

Gjykata Europiane e të Drejtave të Njeriut ka një praktikë të gjërë lidhur me nenin 8 të KEDNJ me këto teknika të posaçme të hetimit. Neni 8 i KEDNJ-së nuk është një e drejtë absolute, pra shtetet kanë marzh të gjërë vlerësimi dhe ato mund të marrin masa në legjislacionin e tyre për ta kufizuar atë për një interes më të lartë, siç mund të jetë siguria publike.

GJEDNJ ka vendosur disa kritere bazë në mënyrë që teknikat e posaçme të hetimit të konsiderohen të ligjshme si dhe provat e marra prej tyre të mund të jenë të përdorshme.

Garantimi i të drejtave të njeriut e përkatësisht i të drejtës për jetë private e familjare është sfidë për shtetet sot, në mënyrë që të mund të ruhet një balancë mes saj dhe sigurisë publike. 
Ina Hasankolli

\section{Referenca}

1. Neni 294/a/1 i Kodit të Procedurës Penale.

2. Vendimi i Gjykatës së Lartë, Kolegji Penal nr.201 datë 05/07/2012.

3. Neni 294/a/2 i Kodit të Procedurës Penale.

4. Vendimi i Gjykatës së Lartë, Kolegji Penal nr.85 datë 06/03/2013.

5. Islami H., Hoxha A., Panda I., Procedura Penale, Tiranë, Botimet Morava ,2012, fq. 458.

6. Neni 294/b/1 i Kodit të Procedurës Penale.

7. Vendimi i Gjykatës së Lartë, Kolegji Penal nr.201 datë 05/07/2012.

8. Neni 294/b/3 i Kodit të Procedurës Penale.

9. Dorëzimi i kontrolluar - Shtuar me ligjin nr. 35/2017, datë 30.3.2017.

10. Ligji nr.8750, datë 26.3.2001 "Për parandalimin dhe luftën ndaj trafikut të substancave narkotike ose psikotrope".

11. Neni 294/c/2 i Kodit të Procedurës Penale.

12. Neni 294/c/4 i Kodit të Procedurës Penale.

13. Neni 8/1 i KEDNJ.

14. Pradel J., Corsten G., Vermeulen G., E drejta penale evropiane, Tiranë, Botimet Papirus, 2009, fq. 404, 406.

15. Pradel J., Corsten G., Vermeulen G., E drejta penale evropiane, Tiranë, Botimet Papirus, 2009 , fq.405.

16. Neni 8/2 i KEDNJ.

17. Vendimi i Gjykatës së Lartë, Kolegji Penal nr.85 datë 06/03/2013.

18. Teixera de Castro vs Portugalisë 09-06-1988.

19. Vendimi i Gjykatës së Lartë, Kolegji Penal nr.201 datë 05/07/2012. 